\title{
LÍNGUA PARA TODES: UM OLHAR FORMAL SOBRE A EXPRESSÃO DO GÊNERO GRAMATICAL NO PORTUGUÊSE A DEMANDA PELA LÍNGUACGEMJ INCLUSIVA
}

\author{
LANGUAGE FOR ALL: A FORMAL VIEW ON THE EXPRESSION OF GRAMATICAL GENDER IN PORTUGUESE \\ AND THE DEMAND FOR AN INCLUSIVE LANGUAGE
}

\section{RESUMO}

No intuito de contribuir para a discussão sobre uma linguagem inclusiva e chamar a atenção para um tema pouco investigado no Português, o objetivo deste artigo é, a partir de uma perspectiva de análise linguística voltada ao estudo estrutura da língua, analisar a plausibilidade de estratégias já utilizadas para a neutralização de gênero gramatical, tais como o uso de '@', '-x’ e '-e'. Veremos que nenhuma dessas estratégias é plenamente satisfatória para a estrutura da língua, de acordo com o conhecimento empírico e bases teóricas disponíveis. Vale, no entanto, insistir no debate, uma vez que há uma defasagem na investigação linguística sobre gênero gramatical no Português se comparada a pesquisas realizadas em outras línguas.

Palavras-chave: Gênero gramatical. Português. Língua inclusiva. Linguística formal.

\section{ABSTRACT}

The aim of this paper is to offer a contribution from the formal Linguistics theoretical approach to the demand for an inclusive language, by analyzing the plausibility of adopting well-known gender neutral strategies - like the use of '@', '- $x$ ' e '- $e$ ' - in Portuguese. As a conclusion, according to the available empirical and theoretical studies, none of these strategies is satisfactory. It is worthy, however, to insist in the investigation of gender expression phenomenon in Portuguese, since there is still a lot to be explored by linguists on this matter, when compared to the studies on linguistic gender expression that have been developed for other languages.

Keywords: Grammatical gender. Portuguese. Inclusive language. Formal Linguistics.

\section{Introdução}

A partir de uma perspectiva de análise linguística voltada ao estudo da estrutura da língua, o objetivo deste artigo é analisar a plausibilidade de estratégias já utilizadas, como o uso de '@', '-x’ e '-e', no intuito de contribuir para o debate sobre uma linguagem inclusiva. A justificativa se dá, em parte, pois muitos linguistas assumem que o masculino é um neutro generalizante e não marcado, enquanto o feminino é

Ana Lucia Pessotto

Doutora em Linguística / Pós-Doutorado em Linguística pela Universidade Federal do Rio de Janeiro. E-mail: anapessotto@gmail.com 
marcado e específico, seguindo a proposta seminal de Câmara Jr. (2006[1970], 1973). Essa visão é criticada por quem defende uma linguagem inclusiva, pois entende-se que o uso do masculino como generalizante opera no discurso um posicionamento sexista estruturalmente fixado sócio-historicamente. Por outro lado, propostas para uma linguagem inclusiva veem a língua como um veículo social (o que também é, mas não só), sem considerar as restrições da organização interna da língua, ou tomando como referência apenas os estudos tradicionais (ver, por exemplo, Rio Grande do Sul, 2014).

Neutralizar o gênero gramatical, como entendido aqui, não é sobre escolher palavras ou o modo de compô-las no discurso. Essas estratégias são parte do uso da língua, definido contextualmente e permeado por questões sociais, históricas, culturais e ideológicas. Já neutralizar gênero gramatical por meio de estratégias artificiais é uma interferência na estrutura da língua, na forma como o sistema se organiza, causando consequências para todo o sistema. Estratégias populares para neutralização de gênero gramatical são o '@’ como marcação da binaridade e, a partir da década de 1980, com a Teoria Queer, o 'x' (remetendo à variável incógnita da matemática) para neutralizar o mesmo binarismo e representar melhor o leque de identidades de gênero. Além dessas, especificamente para o Português, encontra-se a proposta do uso de 'æ' para neutralizar palavras com tema em '-e', como 'eles', que seria grafada 'elæs' quando se referir a um grupo misto'. Finalmente, encontra-se o uso do '-e' para marcar neutralidade em palavras em que há oposição binária, como 'alunes', para a qual vai pender a análise neste artigo.

Essas estratégias são vistas com preocupação por alguns linguistas em razão de questões que surgem quando se tenta interferir na organização interna da língua. Primeiro, a mudança inerente a qualquer língua não se dá por imposição, além de levar anos para ser consagrada pelo uso. Segundo, a fala é um contínuo organizado de sons, cuja sequência segue regras internas à língua. Terceiro, nosso sistema de escrita é regido pelo critério fonológico, ou seja, procura representar aproximadamente os fonemas pelas letras, de modo que, quando chegamos à escola, associamos o conhecimento internalizado sobre a língua oral ao processo de aprendizagem de escrita e leitura. Essas preocupações legítimas, no entanto, não devem entravar o compromisso científico do linguista de observar seu objeto de estudo e descrever os fenômenos que surjam ao longo do seu desenvolvimento. Hoje, é inegável que a neutralização de gênero gramatical é um fenômeno recorrente, que pode ser verificado em diversos meios de comunicação, desde redes sociais e vídeoblogs (por exemplo, o youtuber Claudio Rizzi (2018) invariavelmente inicia seus vídeo com a saudação ‘Oi, você! Oi, menines!'), até títulos de livros, como o recente Feminismo em comum: para todas, todes e todos, de Márcia Tiburi (2018) (Figura 1).

1 Disponível em http://www.artigos.com/artigos-academicos/46o1-a-proposta-do-portugues-cominclusao-de-genero 
Figura 1: capa do livro Feminismo em comum: para todas, todes e todos.

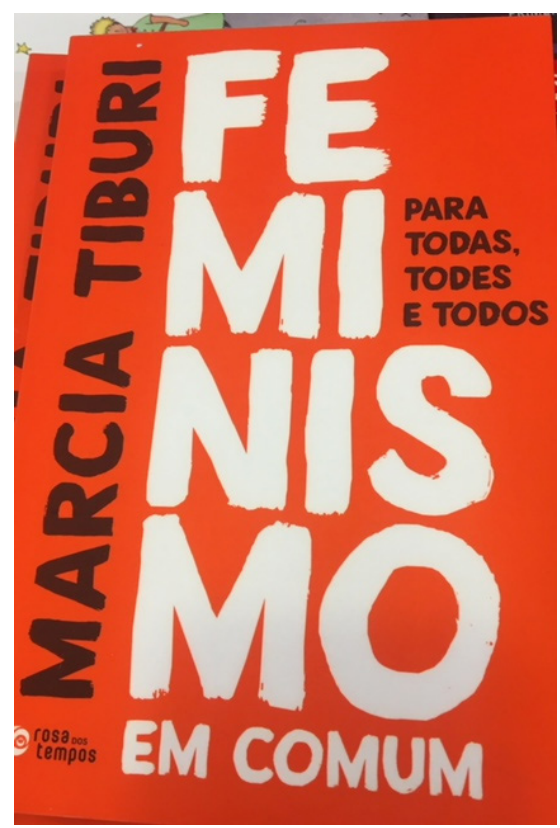

Foto: $\operatorname{xxxx}(2018)$

Este trabalho, portanto, traz uma contribuição do conhecimento sobre a estrutura da língua para a demanda da língua inclusiva, e parte do seguinte questionamento: se formos adotar uma estratégia de neutralização de gênero gramatical dentre as já utilizadas, qual seria a melhor, conforme as regras que governam o Português Brasileiro e o aparato teórico disponível? E mais, seria plausível adotar uma estratégia? Para isso, nos debruçaremos sobre bibliografia básica em Linguística. Veremos, na seção 2, que a marcação de gênero gramatical é inescapável: todo substantivo no PB expressa gênero obrigatoriamente, assim como expressa número, mas com estratégias de marcação variadas. Portanto, alcançar a neutralidade exige que se imponha mudanças na estrutura da língua, o que não é simples. Por ser a proposta de referência na Linguística brasileira, apresentarei na seção 3 a análise de Câmara Jr. (2006[1970], 1973), e outras na mesma linha. Na seção 4 discorrerei sobre as regras fonotáticas da língua, que regulam a combinação dos segmentos sonoros formadores do contínuo inteligível da fala, e como essas regras são caras à aquisição de linguagem falada e escrita. Como conclusão, mesmo a estratégia mais condizente com a organização interna da língua, o uso do '-e', reflete drasticamente em todo o sistema, e sustenta a dúvida de que seja realmente plausível a adoção dessas estratégias, conforme o ferramental teórico e conhecimento empírico atualmente disponível. Ao final, na seção 5, apresentarei um breve panorama dos estudos sobre expressão de gênero em outras línguas, com o intuito de indicar a vasta bibliografia internacional sobre o tema, e veremos que a questão da expressão de gênero gramatical no PB ainda carece, e muito, de ser explorada pelos linguistas. 


\section{Perspectivas linguísticas sobre a expressão de gênero e a expressão de gênero nas línguas do mundo}

As perspectivas teóricas em Linguística podem ser grosseiramente divididas em duas grandes visões: a teoria da estrutura da língua e a teoria do uso. Linguistas interessados no estudo da língua em uso focam fenômenos como a maneira como o falante decide organizar uma sentença de acordo com a sua atitude, intenção ou posicionamento diante do tema, que são fatores sociais externos ao sistema da língua. É na seara do uso, portanto, que o falante coloca sua atitude, enviesando o seu discurso por meio da escolha das palavras, entonação de voz, construção de sentença e conteúdo de ideias expresso.

Por outro lado, os teóricos voltados à estrutura se interessam em explicar a organização interna da língua, descrever as regras que a governam e que são internalizadas por seus falantes. Por exemplo, como sabemos que uma sentença como 'A moça bonito leu o livro' é uma sentença agramatical no Português? Intuitivamente sabemos que precisamos concordar substantivo e adjetivo em gênero: se 'moça' é feminino, seus adjetivos devem estar na forma feminina, por questão de concordância. Essa análise dispensa a computação de fatores externos à língua. Por mais machista que seja um falante não vai produzir a sentença 'A moça bonito leu o livro', ou se referir à moça como 'o moço', pois a concordância de gênero o nome adjetivado é inerente à gramática da língua e é de atribuição obrigatória: não há como muda-la ao bel prazer de cada um. Todo falante do Português sabe que 'moça bonito' não é uma expressão que segue a regra de concordância da nossa língua nativa, um conhecimento internalizado no decorrer da aquisição da língua e independente de idade, classe, credo, ideologia ou origem geográfica. É a essa vertente da Linguística a que se alinha este artigo.

Os teóricos da estrutura da língua pouco disseram até hoje sobre a expressão de gênero gramatical no Português desde a proposta seminal de Câmara Jr. (2006[1970], 1973). Segundo o autor, a forma gramatical conhecida como masculina é, na verdade, não-marcada para gênero, expressando tanto o gênero neutro quanto o masculino, a depender do contexto. Um exemplo ilustrativo é quando vemos um grupo de animais, por exemplo, gatos. Ao avistá-los podemos dizer algo como "Olha lá, quantos gatos!", sem precisarmos saber se são todos machos, todos fêmeas, ou ambos. Já a forma conhecida como feminino expressa uma especialização, e é a forma marcada para gênero. Usando o mesmo exemplo, só diríamos “Olha lá quantas gatas!" se tivéssemos certeza que todas do grupo fossem fêmeas. Estas são questões intuitivas do uso da língua que corroboram a perspectiva de gênero não-marcado como generalizante, e o marcado como restrito. Essa visão é passível de críticas de quem defende uma língua inclusiva, pois é socialmente questionável a ideia de que a forma feminina represente uma "subespécie" da masculina.

A título de reflexão, um equívoco comum é assumir que a palavra 'mulher' é o feminino de 'homem'. Na perspectiva linguística essa afirmação é incorreta, pois embora sejam palavras relacionadas semanticamente, não o são morficamente. São 
simplesmente duas palavras diferentes: 'homem' é sempre masculino e designa seres humanos do gênero masculino, enquanto 'mulher' é sempre feminino, e designa seres humanos do gênero feminino. Felizmente, ao que parece, sabemos disso, e usamos outras estratégias para generalizar: ao avistarmos um grupo de seres humanos, espontaneamente não proferiríamos "Olha lá, quantos homens", mas sim “Olha lá quantas pessoas", ou "quanta gente”, ambos substantivos femininos e que expressam um conjunto da mesma espécie, pois possivelmente já entendemos intuitivamente que 'homens' designa um subgrupo da espécie, e não a espécie toda. Usar 'homem' para referir-se à humanidade é, portanto, uma questão de escolha (o uso), e não obrigatória.

Retornando à questão de como a Linguística trata a marcação de gênero, o gênero gramatical é entendido como uma maneira de organizar as palavras nominais em classes relacionadas semântica e morficamente. Para Câmara Jr. (1970, p. 88), “é uma distribuição em classes mórficas para nomes, da mesma sorte que as conjugações para os verbos”. A marcação de gênero aparece em pelo menos um quarto das línguas do mundo, de forma obrigatória, ou seja, nas línguas que apresentam gênero gramatical, a atribuição do gênero ao substantivo é indispensável. No Português, gênero e número são classificações inerentes a qualquer substantivo: todos são marcados como feminino ou masculino, singular ou plural. $\mathrm{O}$ fato de as línguas indo-europeias apresentarem a distinção dual de gênero como critério de classificação (com algumas incluindo o gênero neutro, como o Inglês e o Alemão), leva a três conclusões equivocadas e não-científicas: primeiro, a que o gênero gramatical corresponde ao sexo; segundo, que feminino e masculino são a única forma de classificar substantivos; terceiro, que a expressão de gênero se restringe à oposição '-a' vs. '-o', para marcar feminino e masculino, respectivamente. Tais conclusões são frágeis ao mais leve escrutínio, como veremos.

Começamos pelo terceiro equívoco, que é generalizar que substantivos terminados em '-o' são masculinos e os terminados em '-a' são femininos. Uma reflexão rápida sobre as palavras do Português nos traz exemplos como 'poeta', 'planeta' e 'cometa', todas terminadas em '-a' e do gênero masculino; também 'ponte' e 'cabide', que não terminam nem em '-a', nem em -o, mas em -e, e a que se atribui, respectivamente, gênero feminino e masculino. Há ainda os nomes terminados em consoante, como 'dor', 'amor', 'lápis', 'anel', a que se atribui à primeira gênero gramatical feminino, e às demais, masculino. Palavras terminadas em '-ista' que designam profissões são comuns para qualquer gênero, e palavras como 'vítima' e 'testemunha', que terminam em '-a', são gramaticalmente femininas, mas podem designar pessoas de qualquer gênero. Esses exemplos mostram que não há uma relação biunívoca entre a terminação da palavra e o gênero gramatical expresso ${ }^{2}$.

2 O fato de a marcação de gênero gramatical no Português se realizar em feminino vs. masculino e não se restringir à oposição '-a'vs. '-o' é em parte explicado pela maneira como essa língua se desenvolveu a partir do Latim. Por questões de espaço, optei por não apresentar os fatos da história da língua, que envolvem a queda das declinações e do gênero neutro do Latim nas línguas românicas modernas. Ao leitor interessado, ficam algumas referências sobre o assunto: Teyssier (1997), Ilari e Basso (2006); Gonçalves e Basso (2010). 
O segundo equívoco é acreditar que feminino vs. masculino são a única forma de classificar substantivos. A estratégia de classificação dual de gênero não é a única, e muitas línguas sequer apresentam essa marcação. Línguas como o Coreano, o Japonês, o Turco, o Mongol, outras línguas sino-tibetanas e algumas línguas nativas norte-americanas não classificam as palavras em gênero, mas podem apresentar outras estratégias de classificação. Tiramos alguns exemplos de Câmara Jr. (1973). O Malaio utiliza o traço humano3: há maneiras de marcar morfologicamente se a palavra designa um ser humano ou um animal de cauda, ou um objeto redondo. Algumas línguas Bântu têm vários gêneros com prefixos correspondentes, e classificam no mesmo grupo pessoas e "animais superiores", separado de outros animais. A língua Haida, do Alasca, entre suas 36 classes nominais (!), marca a classe dos filamentos: cordas, cordões, fitas, cabelos, lombrigas, toda palavra que designa um ser ou objeto em forma de filamento é marcada com o morfema - sga $^{-4}$. O Chinês apresenta morfemas classificadores para expressar as quantidades, e cada classificador é específico de um grupo de substantivos relacionados semanticamente. Assim, há um classificador específico para coisas ou animais longos e finos, outro para objetos com cabo, outro para objetos que podem ser contatos em folhas (como fotos) e assim por diante. O Russo tem um sistema misto, que marca tanto feminino e masculino como também animacidade por meio de interação entre os casos morfológicos, enquanto o Japonês não marca feminino e masculino, mas marca a animacidade por meio da escolha dos verbos de existência ou posse que acompanham o substantivo.

O critério gênero é, então, só um entre tantos para classificar os substantivos, e também não pode ser confundido com a expressão do sexo ou do gênero quando se refere a pessoas, o que nos leva ao primeiro grande mal-entendido citado. Uma consulta ao dicionário mostra que a proporção de substantivos que têm o gênero relacionado a sexo é pequena, se considerado o número total de substantivos. Rocha (1982) traz que $95,5 \%$ dos substantivos se referem a seres não-sexuados. Os $4,5 \%$ que se referem a seres sexuados nem todos recebem marca morfológica de gênero, com vários exemplos como 'criança', 'testemunha', 'mulher'. Ou seja, quase todos os substantivos do Português possuem um gênero único, que é marcado por uma estratégia (morfo)sintática, ou seja, por concordância de gênero a partir da flexão dos demais elementos da sentença: 'o livro amarelo', 'a testemunha intimada', etc.

Assim, nomes com marcação de gênero relacionado a sexo restringem-se aos que designam humanos ou animais, seres tipicamente sexuados. Mesmo entre esses, a oposição de gênero gramatical não é unânime. Além dos exemplos acima, nomes terminados em '-ista' ('jornalista', 'dentista', 'linguista', 'motorista'), assim como muitos nomes de animais (como 'cobra', 'baleia', 'tigre') por exemplo, não

3 Câmara Jr (1973) usa a palavra "pessoal" para indicar a divisão entre pessoas e coisas. Optei por usar o termo traço humano, que julgo mais moderno e, hoje em dia, mais usado.

4 "assim, em / dãgilsgalu'nal/ "três cordões", entre o nome /dãgil/ "cordões" e o numeral /lu'nal/ "três", vem o morfema '-sga-' próprio dos nomes da classe dos filamentos." (CÂMARA Jr., 1973, p.132) 
marcam oposição de gênero5. Quanto a nomes como 'estante', 'sofá', 'tiro', 'amor', 'dor', 'problema', mesmo assim apresentam gênero gramatical, sendo a eles atribuído gênero feminino ou masculino mesmo que não designem entidades sexuadas e não tenham gênero morfologicamente marcado.

A marcação de gênero gramatical é, portanto, um fato linguístico, uma estratégia de classificação dos nomes nas línguas humanas, que variam em suas estratégias para tal fim. Existe não somente a classificação por gênero, mas também por animacidade, traço humano, contagem, forma, e outros. Além do equívoco de restringir o gênero à dicotomia feminino-masculino, há ainda a inadequação em se associar gênero gramatical a sexo, dado que a grande maioria dos substantivos sequer designam entidades sexuadas.

Delineada a compreensão da Linguística sobre o gênero gramatical, partimos à apresentação da proposta clássica de Câmara Jr. sobre o mecanismo da marcação de gênero no $\mathrm{PB}$, bem como outras propostas na linha estruturalista, uma vez que essas fornecem as ferramentas de análise a que os linguistas em geral mais recorrem ao tratar do tema.

\section{Bases teóricas sobre a marcação de gênero gramatical no PB}

Para compreendermos o tratamento dado pela Linguística formal à expressão de gênero no Português, discorro nesta seção sobre duas propostas de explicação: a proposta seminal de Câmara Jr. (2006[1970], 1973) amplamente aceita pelos linguistas, por ser econômica e coerente com a história da língua; e a de Rocha (2008), também de cunho estruturalista, mas que traz um contraponto.

Primeiramente, nem toda a vogal final de um substantivo marca gênero, ou seja, nem todo '-o' ou '-a' final é marcação de gênero, pois, na maioria das vezes, a vogal final é uma vogal temática. Segundo Câmara Jr. (2006[1970], p.86), o tema é “o radical ampliado por uma vogal determinada que entra na flexão de nomes e verbos”. Para o autor, há temas em '-a' ('rosa', 'poeta', 'planeta'); temas em '-o' (átono final, como 'livro', 'tribo') e os temas em '-e' (átono final, como 'ponte' e 'dente') e, dessa forma, não se deve confundir o '-a’ final que seja desinência de feminino (como 'aluna' em oposição a 'aluno') com um '-a' final que seja vogal temática, como em 'artista' e 'dentista'. O '- $a$ ' final dessas palavras não marca gênero, pois não há oposição com \#'dentisto' e \#'artisto', portanto, em casos como esses não haveria razão para usar estratégias de neutralização (como 'dentist@', ou 'dentistx'). Veja que não há nada na

5 Acrescentar 'macho' ou 'fêmea' a um substantivo como 'cobra' não é marcação de gênero, mas uma aposição de substantivos para expressar o sexo do animal, e é de uso opcional, diferente da marcação grammatical de gênero, que é morfológica ou sintaticamente obrigatória. Por exemplo, o substantivo 'cobra' é sempre feminino, exigindo concordância do adjetivo, mesmo com o acréscimo de 'macho': 'a cobra macho amarela', 'a cobra fêmea amarela'.

6 Uso \# para indicar uma ocorrência inadequada, ou não usada, apesar de possível conforme as regras da língua. 
estrutura dessas palavras que as impeça de serem palavras do PB: são pronunciáveis e de acordo com regras morfofonológicas do PB. Porém, não são de uso. Observe, por exemplo, o termo "feministo" (usado para referir ao homem que se diz "feminista", mas reproduz comportamento machista), que é de uso corrente em uma comunidade de fala específica e segue a mesma lógica de produção de 'linguisto'.

Câmara Jr. (2006[1970]), aponta ainda os substantivos que não possuem vogal temática (atemáticos), que englobam os substantivos oxítonos ('peru', 'alvará', 'chulé'). Nomes que, no singular, terminam em consoante, o autor assume que tenham vogal temática teórica '-e', deduzida dos plurais. Por exemplo: 'feliz'-felizes'; 'dor'-'dores'; 'professor'-'professores'. Note que, neste último exemplo, portanto, também não há indicação linguística para neutralização como 'professor@s' ou 'professorxs', pois '-e' é vogal temática e não marca gênero. Uma das explicações para a vogal teórica é que ela é resgatada do Latim ('dolore', por exemplo) para atender às regras fonotáticas do Português, que não aceita encontros consonantais como /rs/ ou /zs/7 (ver seção 4).

Quanto à marcação morfológica de gênero, o autor defende que é um tipo de flexão, e é uma só, como regra geral: o acréscimo de '-a' átono final, com a supressão da vogal temática '-o' quando ela existe no singular. Assim, '-o' em palavras como 'aluno' não marcam gênero, mas são vogais temáticas. $O$ masculino não é marcado, ou seja, a oposição 'aluno'-'aluna' não se dá pela oposição entre '-a' e '-o', mas entre '-a’ e um morfema nulo ‘Æ’ para gênero gramatical, já que não há marcação de gênero masculino: o ‘-o’ final seria vogal temática. A supressão do '-o’ para formar 'aluna' seria uma acomodação fonológica, para não termos uma pronúncia incômoda como *'alunoa'. Palavras atemáticas não têm esse problema quando flexionadas no feminino: 'peru' se flexiona em 'perua' apenas com o acréscimo de '-a'. 'Professor' e 'doutor' flexionam em 'professora' e 'doutora' da mesma forma. Já 'dentista' (e as demais com a mesma terminação '-ista’) não flexiona, pois '-a' final é vogal temática, e não marca gênero.

Além da marcação de gênero com acréscimo de '-a' ao final como regra geral, Câmara Jr. (2006[1970], p. 90) analisa marcações alternativas, ou alomorfes ${ }^{8}$ de gênero. As alternativas incluem palavras como 'avô' e 'avó', cujo gênero é diferenciado por alternância vocálica; o mesmo ocorre com 'grosso' e 'grossa', nesse caso com a adição da marcação regular '-a'; casos com sufixo '-ão', na forma teórica /oN/, transfere o travamento nasal para o fonema seguinte e gera /-ona/, como em 'valentão'-'valentona'; os radicais em /aN/ com tema em '-o', como 'orfão' e 'irmão', somente suprimem a vogal do tema no feminino e ficam 'órfã' e 'irmã'; casos como 'europeu', em que o sufixo '-eu' que, embora termine em '-u', a vogal temática é '-o', e é suprimida para o acréscimo de '-a' - 'europea' - e a posterior ditongação natural

7 A vogal temática teórica encontra evidência também em línguas aparentadas derivadas do Latim, como o Italiano, em que a vogal se manteve na forma singular ('felice'; 'dolore'; 'professore'), e os processos de marcação de gênero seguiram outras estratégias (It.: professore - professoressa), aplicadas inclusive em algumas palavra do Português ('conde'-'condessa').

8 Alomorfes são duas ou mais formas diferentes que expressam o mesmo significado, ou têm a mesma função. 
entre /e/ e /a/ no Português, gerando 'europeia'. Casos como 'imperador'-imperatriz'; 'galo'-'galinha', 'perdiz'-'perdigão', o autor trata como casos de derivação, e não flexão, pois são formados por sufixos derivacionais: '-triz, '-inha' e '-ão', respectivamente. Esse tratamento duplo da marcação de gênero, ora por flexão, ora por derivação, é um dos pontos criticados por Rocha (2008), como veremos ao final da seção.

A estratégia para identificar se a vogal final marca gênero ou não é estabelecer um par opositivo. Sabemos que o '-a' de 'aluna' marca gênero pois temos a oposição com 'aluno', que não tem marca de gênero, apenas a vogal temática '-o', que é suprimida na flexão por acomodação fonotática. O mesmo se observa em 'professora': sabemos que o '-a' marca gênero pois há oposição com 'professor', que não tem marca morfológica de gênero (e nem vogal temática). Já 'dentista', 'artista', 'atleta', não encontram oposição, pois não usamos palavras como \#'dentisto', \#‘artisto’ e \#'atleto'; logo, o '-a' final daquelas palavras não marca gênero, é vogal temática. Se não marca gênero, não há razão para usar estratégias de neutralização como \#'dentistx', \#'artistx' e \#'atletx'. Da mesma maneira não faz sentido incluir 'x' ou '@' em verbos, como na expressão \#"somxs todxs...”, como apontado em Roloff e colegas (2015). Verbo não apresenta marcação de gênero em Português, apenas de tempo e número.

Uma análise alternativa é a de Rocha (2008). Baseado no fato de a maioria dos substantivos no Português não apresentarem marca morfológica de gênero e apenas uma minoria se referir a seres sexuados, Rocha afirma que "o gênero do substantivo é indicado por um expediente sintático” (p. 191) e o processo de marcação de gênero em termos referentes a seres sexuados se dá por derivação, e não flexão. $\mathrm{O}$ autor argumenta que, tendo a maioria dos substantivos um gênero sem marca morfológica, a identificação do gênero gramatical se dá pela concordância exigida para os demais termos da sentença, o que seria, esse sim, sim um processo flexional: obrigatório, regular e previsível. No exemplo "a testemunha foi intimada a depor", em primeiro lugar não há morfologia de gênero no substantivo e não há referência ao sexo ou à identidade de gênero da testemunha; no entanto, há o gênero gramatical feminino, que exige a concordância em gênero do artigo e do adjetivo para que seja uma sentença gramatical na nossa língua. Este processo de concordância com o substantivo se dá pela flexão de gênero no artigo 'a' e no adjetivo 'intimada', mesmo que 'testemunha' se refira a um homem.

Já sobre a marcação morfológica de gênero, Rocha (2008) defende que se dá pela aplicação de regras morfológicas de derivação. $\mathrm{O}$ autor compara a marcação de gênero com a marcação de número, e mostra que, enquanto esta é regular e previsível (para fazermos plural, acrescentamos o '-s', invariavelmente) a marcação de gênero é irrregular e imprevisível, caracterizando um processo derivacional. $\mathrm{O}$ autor cita palavras que no feminino recebem a terminação '-esa' ('portuguesa'), '-essa' ('condessa'); '-isa' ('poetisa'); '-ina' ('czarina'); '-inha' ('galinha'), já tratadas por Câmara Jr. como derivações e não flexões. Rocha (2008) então propõe tratar todas as marcas morfológicas de gênero como um sufixos derivacionais, pois, se considerarmos '-a' como sufixo flexional, nem sempre a regra se aplica, já que a produção de itens lexicais femininos pela adição de '-a' é bastante irregular. O autor fornece uma extensa lista 
de substantivos em que a regra não se aplica (p. 211) como pedestre-(?)pedestra; urubu-(?)urubua; coronel-(?)coronela; rival-(?)rivala.

Essas "falhas" no sistema evidenciam a característica derivativa do gênero, pois mostra restrições à produção de itens lexicais. Além disso, essas restrições são imprevisíveis: por que razão a regra se aplica a 'professor-professora', mas dizemos 'consulesa' e não 'cônsula', como preveria uma regra flexional como a de número?9 Rocha (2008) não se detém na discussão sobre a característica neutra do masculino, porém, se alinha a essa posição dizendo (p. 209) "o uso [...] no masculino não quer dizer, necessariamente, que seja uma referência explícita a seres do sexo masculino, mas pode tratar-se de um emprego geral, em que não se pode ou não se quer explicitar o sexo do referente".

Nesta seção, apresentamos algumas propostas conhecidas para o tratamento da expressão de gênero no Português. Começamos apresentando a proposta de Câmara Jr. (1970, 1973), bem como a proposta alternativa de Rocha (2008). A adequação destas propostas à realidade psicológica dos usuários da língua, no entanto, ainda carece ser estudada ${ }^{10}$. Passamos agora para uma exposição sobre as regras fonotáticas da língua e sua relação com a aquisição de fala e escrita.

\section{A fonotática, a escrita, e uma (possível?) estratégia para a neutralização de gênero gramatical no PB}

Nesta seção serão apresentadas duas questões cruciais sobre a organização da língua e a aquisição de escrita diretamente relacionadas à adoção de uma estratégia de neutralização de gênero gramatical. São elas a fonotática, que governa a organização dos sons na língua, internalizada durante o período de aquisição da fala; e a aquisição de escrita, que exige treinamento formal e, em parte, depende do conhecimento internalizado sobre a organização dos sons da língua na fala.

Dentro da perspectiva aqui adotada, a língua falada é naturalmente adquirida, numa combinação entre nosso aparato genético e a exposição a uma língua no meio social, que "dispara" a habilidade da linguagem. Por isso é comum dizer-se que a língua emerge no ser humano, espontaneamente: ninguém precisa ensinar formalmente uma criança a falar para que ela fale. Por outro lado, a escrita é artificial e necessita de treinamento formal. Os sistemas de escrita são invenções culturais, criadas como ferramenta para registrar conteúdos, pensamentos, ampliando a nossa capacidade de memória e promovendo a documentação.

9 Rocha (2008) aponta, nesses casos, a importância de se observar a imprevisibilidade com relação aos itens cristalizados, às vezes herdados historicamente, e a improdutividade no estágio atual da língua (por exemplo, dificilmente seria criado um substantivo feminino novo com o acréscimo de sufixos como '-essa', '-triz', etc. O sufixo produtivo é '- $a$ ').

1o Sobre esta questão, alguns trabalhos sobre o Inglês podem ser encontrados: Cole et al (1983) e Chesnut (2010), e referências destes, além das referências apresentadas ao final deste texto. 
Conforme Scliar-Cabral (2015), os sistemas de escrita evoluíram, desde os sistemas icônicos (como os hieróglifos), passando pelos ideográficos, silábicos e, finalmente, os alfabéticos, como o nosso. O critério de evolução" considerado é a aproximação do sistema de escrita à arquitetura do sistema oral. Portanto, é característica das letras do alfabeto representarem fonemas, mesmo que de forma imperfeita (Morais e Kolinski, 2015). A escrita alfabética se organiza para representar os segmentos sonoros do inventário daquela língua e acompanhar as regras de organização dos fonemas no contínuo da fala. Sendo que a fala emerge antes da escrita, levamos à escola o nosso conhecimento já internalizado sobre o inventário de sons, seu valor, e a organização deles na nossa língua materna. Tendo o sistema alfabético se desenvolvido de modo a se aproximar da língua oral, é natural que aprendamos a escrever e ler "procurando" correspondência entre a organização de sinais visuais (as letras) e os sinais sonoros que já conhecemos (os sons da língua).

Parte desse conhecimento adquirido na fase de aquisição da língua oral é composto pelo sistema fonotático da língua, ou fonotática. O termo diz respeito ao "levantamento dos padrões fonêmicos permitidos" em uma língua (Callou e Leite, 1990), ou seja, tais regras especificam as sequências de sons possíveis e as impossíveis em uma língua, para que obtenhamos o contínuo inteligível, expresso na fala. Por exemplo, na língua inglesa, a sequência /rl/ é uma sequência possível, observada em palavras como 'world', porém, bloqueada no Português, o que torna difícil para um falante nativo pronunciar essa sequência. O estudo fonotático observa a sílaba, uma unidade difícil de definir, mas que configura a unidade mínima de articulação de sons linguísticos ${ }^{12}$.

Simplificando a descrição de Silva (2015), no PB as sílabas são obrigatoriamente constituídas de vogais $\mathbf{V}$, que compõem o núcleo silábico, e eventualmente apresenta consoantes $\mathbf{C}$ nas partes periféricas. Em outras palavras, a sílaba é constituída, pelo menos, por uma vogal, como a primeira sílaba de 'á-gua', não sendo possível uma sílaba sem vogal. O preenchimento das posições periféricas é opcional e pode seguir as seguintes configurações: uma ou duas consoantes pré-vocálicas (como a primeira e a segunda sílaba de 'li-vro'); uma ou duas consoantes pós-vocálicas, como a primeira e a segunda sílabas de 'trans-por-te'. Sílabas com consoante na posição final (a coda silábica) são chamadas sílabas travadas, enquanto as terminadas em vogal são sílabas livres.

Com essas informações, é possível já observar a inadequação linguística de uma estratégia como o ' $x$ ' e ‘@’ para a neutralização de gênero. A letra <x> corresponde a alguns fonemas como /z/ ('exemplo'); / / ('xale'); /s/ ('paz'); /ks/ ('tóxico'), a depender do ambiente em que se encontra na sílaba. Nenhum desses sons pode ser encontrado como núcleo de sílaba no PB, e essa informação compõe o conhecimento intuitivo que adquirimos sobre a organização dos sons da nossa língua. Assim, uma palavra

11 Aqui entendo o termo ‘evolução’ como referente a uma questão cronológica, por ordem de surgimento e de difusão de uso. O intuito não é, portanto, apontar escritas ideográficas como menos importantes que as escritas alfabéticas, tampouco superadas por elas.

12 Sobre a definição de sílaba, ver Callou e Leite (1990); Silva (2015), e referências. 
como 'alunxs' é anti-natural para o sistema, pois a segunda sílaba -nxs não atende às regras fonotáticas da língua, já que apresenta encontro consonantal com mais de duas consoantes na mesma sílaba e, mais importante, não apresenta vogal. As regras fonotáticas do $\mathrm{PB}$ não permitem um encontro consonantal com mais de duas consoantes na mesma sílaba e fundamentalmente exigem uma vogal como núcleo de sílaba. Já na escrita, se aprendemos a escrever e ler "procurando" correspondência entre a organização das letras dos sons da língua, a aquisição do padrão <-nxs> enfrentará problemas, pois quem está aprendendo não encontrará correspondência entre a letra $<\mathrm{x}>$ naquela posição e os sons a que ela corresponde, uma vez que traz $\mathrm{o}$ conhecimento tácito de que a língua não permite aqueles sons na posição de núcleo de sílaba em que a letra correspondente se encontra.

Já sobre o uso do '@', neste caso, com base no exposto, não temos como analisar, pois esse símbolo sequer é uma letra do nosso alfabeto ou corresponde a um fonema na nossa língua. O mesmo se tem a dizer sobre a estratégia '-æ'.

Dado o exposto até aqui, uma estratégia já em uso e que atenderia a essas regras é o uso de '-e'. Sendo uma vogal, '-e' pode figurar como núcleo de sílaba e compor uma palavra neutra como 'alunes', atendendo às regras de organização dos sons da língua como estratégia de neutralização de gênero. No entanto, a solução não é tão simples. Muitas palavras não seriam contempladas por essa estratégia, pois a marcação de gênero varia para além da aparente oposição '-o' vs. '-a'. Além disso, sendo a língua um sistema, qualquer alteração em uma parte dela reflete alterações no sistema todo. É preciso, portanto, retornar à proposta teórica de análise exposta na seção 3 para observarmos quais termos podem ser neutralizados sob essa estratégia e vislumbrar os problemas que ela acarretaria.

O uso de '-e' serviria para neutralizar gênero apenas em palavras em que a oposição gramatical feminino-masculino se dá pela oposição Æ vs. '-a'. Já excluímos, então, como já apontado na seção 3, palavras terminadas em '-e', como 'atendente' e 'assistente', que não têm oposição de gênero marcada morfológica ou fonologicamente, pois 'e' é vogal temática. Também palavras terminadas em '-ista', e palavras terminadas em '-a' como 'testemunha' e 'vítima' ficam excluídas da necessidade de se neutralizar gênero, uma vez que o '-a' final também não marca gênero, mas é vogal temática. Assim, somente palavras como 'aluno', 'menino', 'secretário', 'todo', 'os' poderiam ser neutralizadas para 'alune', 'menine', 'secretárie', 'tode', 'es'.

Essa alteração parece simples se pensarmos na palavra isolada. No entanto, na língua, entendida como um sistema, cada alteração reflete no sistema todo. A língua exige concordância de gênero gramatical, portanto, ao neutralizar com '-e' uma palavra como 'alunes', essa alteração interfere em toda a cadeia relacionada a essa palavra em uma sentença. Sendo assim, para que haja coerência linguística na estratégia adotada, uma sentença como 'Todos os alunos são bem-vindos' deve ser, necessariamente, “traduzida” para 'Todes es alunes são bem-vindes'.

Mesmo entre palavras em que a oposição Æ vs. '-a', a estratégia traria questões a serem enfrentadas na escrita. Palavras masculinas como 'amigo' e 'médico', que se opõe em gênero a 'amiga' e 'médica', precisariam ou de uma maneira para adequar a 
escrita à pronúncia - no caso 'amigue' e 'médique', com a inserção do dígrafo <gu> para continuar correspondendo à pronúncia oclusiva /g/; ou de uma alteração na pronúncia para favorecer a simplicidade na escrita - passaríamos então a escrever 'amige' e 'médice', pronunciando de acordo /ami?le/ e /m?dise/. Como a fala precede a escrita, a hipótese mais amigável à aquisição seria a primeira.

Já com palavras que terminam em consoante, como 'professor' e 'doutor', as quais se opõem e gênero a 'professora' e 'doutora', uma estratégia de acordo com a teoria disponível e empiricamente compatível seria resgatar a vogal temática teórica proposta por Câmara Jr. (2006[1970]), que foi suprimida ao longo do desenvolvimento da língua (ver seção 3 e nota 10). Assim, caso a pessoa designada por essas palavras não se identifique nem com o feminino, nem com o masculino, tem a alternativa de ser chamada de 'professore' e o plural, 'professores', não precisa ser neutralizado, uma vez que - $e$ - é vogal temática e não marca gênero.

Dada análise exposta, partimos para as conclusões. Dentre as estratégias analisadas, duas são logo excluídas - '@'e '-æ' - por não representarem nenhum som da nossa língua e por isso sequer serem letras do nosso sistema de escrita. Além disso, como vimos, a alternativa '@' é baseada em uma concepção equivocada de que a expressão de gênero se dá de forma binária e pela oposição entre '-o' e '-a' finais. Restaram as alternativas '-x' e '-e'. A alternativa '-x', foi excluída com base a nossa análise de base linguística, dado que não se conforma às regras fonotáticas da língua: apesar de $<x>$ ser uma letra do nosso alfabeto, que representa uma família de sons da nossa língua, nenhum desses sons pode servir como núcleo de sílaba no $\mathrm{PB}$, o que traria dificuldades para a aquisição de escrita e sua correlação com a pronúncia. Nos restou a alternativa '-e', a única que se conforma às regras fonotáticas da língua e seria, portanto, mais amigável aos processos de aquisição de língua falada e escrita. No entanto, essa alternativa não é geral o suficiente, pois não cobre todas as formas de marcação de gênero encontradas no PB, se restringindo apenas a formas que apresentam oposição Æ vs. '-a'. Mesmo nesses casos, haveria necessidade de adaptações da escrita, além de refletir em todo o sistema de concordância que rege a língua. Portanto, com base nas linha teórica apresentada sobre a marcação de gênero gramatical no PB, nenhuma das estratégias hoje largamente utilizadas para a neutralização é plenamente satisfatória.

Haveria, então, uma saída linguística favorável à neutralização da marcação de gênero gramatical no Português? Apesar de variação e mudança serem inerentes a qualquer língua, é preciso considerar que i) essa mudança não se dá por imposição e ii) segue um curso sistemático, que leva tempo, e nunca se desgarra abruptamente das regularidades do sistema. Quanto ao primeiro ponto, se imposição tivesse o poder mudar o sistema da língua, todos nós falaríamos e escreveríamos conforme as normas gramaticais ditas "cultas", ou padrão. A gramática normativa, a "do bem falar e do bem escrever", na nossa sociedade configura-se como instrumento impositivo e opressivo na medida que segrega "cultos" e "incultos", privilegiando quem a segue, e marginalizando quem não a segue, gerando o que conhecemos como preconceito linguístico. Ainda assim, a língua varia e muda, pois somos nós, falantes da língua viva, 
que procedemos as variações e consagramos as mudanças, em um comportamento que se pode reconhecer como revolucionário, ainda que inconsciente, diante de forte pressão de uma sociedade linguisticamente conservadora para o uso "correto" da língua.

Relacionado ao segundo ponto, observamos que ideia da neutralização de gênero pelo mundo obtêm vitórias e sofre resistência. Em 2017, por exemplo, o primeiro ministro francês decretou o banimento da linguagem inclusiva dos documentos oficiais, alinhado aos intelectuais conservadores da Academia Francesa, que julgam a linguagem inclusiva como uma "ameaça à pureza da língua francesa", pois "cria uma confusão que beira o ilegível" ". Por outro lado, em 2015 a Academia Sueca anunciou a inclusão do pronome neutro 'hen' no dicionário da língua, que passou a ser usado junto ao pronome feminino, 'han', e ao masculino, 'hon'. O termo 'hen' surgiu na década de 1960 e, nos anos antes da incorporação ao dicionário, passou a ser largamente utilizado na comunidade trans da Suécia e a aparecer em publicações impressas, jornais, livros e até mesmo em documentos judiciais. O critério para a decisão de incluir a palavra no dicionário é o mesmo usado para a incorporação de palavras em qualquer dicionário: a consagração do termo pelo uso na comunidade de falantes.

Esses exemplos ilustram questões importantes quando se considera impor alterações na língua natural. É consenso que a variação e a mudança são inerentes a qualquer língua: não há língua conhecida que tenha se mantido igual ao longo anos; e, no processo natural de variação e mudança, é fato que toda a inovação linguística sofre resistência. Por exemplo, no PB o pronome 'você' evoluiu historicamente a partir do tratamento 'Vossa Mercê'. Por muito tempo foi visto como uma deturpação da língua, uma vez que o pronome 'tu' era considerado o correto. Foram necessárias décadas de consagração pelo uso para que fosse aceito tanto pelos falantes como pela norma padrão. Hoje, 'você' é mais difundido no Brasil do que 'tu'14. Se a resistência ocorre em uma mudança natural, imagine então quando a mudança é imposta, e a partir de estratégias que não condizem com as regras naturais da língua. Por fim, a consagração pelo uso em conjunto com o respeito às regras fonotáticas da língua foram receita de sucesso no caso da Suécia. Foram quase 60 anos desde que o uso de 'hen' foi documentado e é uma palavra que segue uma sequência de fonemas possível na língua Sueca, o que contribui fundamentalmente, junto a demanda social, para a consagração pelo uso.

De qualquer forma, nos servirão sempre estratégias de uso também já bastante conhecidas, porém não tratadas neste texto, uma vez que, como definido no início, nosso objetivo foi olhar o fenômeno de uma perspectiva a partir da estrutura da língua. O uso, no entanto, nos permite expressar inclusão e neutralidade por meio da escolha das palavras e da construção das sentenças. Por exemplo, saudar uma plateia mista com "Bom dia a todas e todos" em vez de optar pelo alegado masculino neutro

13 Disponível em: <http://www.academie-francaise.fr/actualites/declaration-de-lacademie-francaisesur-lecriture-dite-inclusive>

14 Para mais sobre a variação tu-você veja Scherre et al (2015) e referências. 
"Bom dia a todos" é uma estratégia do uso amigável à estrutura da língua. Uma das críticas que essa estratégia recebe é a falta de economia, pois requer um texto com mais palavras. No entanto, não deixa de ser viável e usada até mesmo em campanhas publicitárias (onde se supõe textos curtos), como na fachada da Casa do Advogado, escritório da Ordem dos Advogados do Brasil no centro do Rio de Janeiro, onde se lê, em dois banners dispostos lado a lado, à esquerda "Sem advogado não há justiça" e à direita "Sem advogada não há justiça (Figura 2). Esta segue, no entanto, sendo uma estratégia binária, que como as estratégias estruturais discutidas, também tem prós e contras.

\section{Um longo caminho a percorrer}

Este artigo partiu do seguinte questionamento: se for o caso de estabelecermos uma estratégia para a neutralização de gênero gramatical no $\mathrm{PB}$, qual seria a melhor estratégia de acordo com os fatos da língua, as estratégias já usadas e os estudos consagrados? Para tanto, discorri sobre alguns conhecimentos básicos sobre a estrutura do $\mathrm{PB}$, propostos e defendidos ao longo de décadas de história da Linguística. Expusemos propostas sobre como o gênero gramatical no PB é tratado na Linguística, em especial proposta de Câmara Jr. (2006[1970], 1973), uma vez que esta é a que ecoa mais fortemente entre os linguistas. Apresentamos as regras fonotáticas da língua, ou seja, a maneira como os fonemas se organizam no contínuo da fala e a relação entre o conhecimento linguístico e a aquisição de escrita. Toda a exposição foi feita com o intuito de sentar bases para esboçar uma análise viável, considerando como, com as ferramentas teóricas disponíveis, se pode analisar as estratégias já largamente utilizadas, como o ‘-x', o ‘@’ e o ‘-e’. Concluímos que, do ponto de vista linguístico e seguindo as ferramentas teóricas apresentadas, a melhor estratégia entre as já utilizadas seria o uso do '-e', por atender melhor à fonotática da língua e, teoricamente, permitir uma aquisição mais natural. No entanto, mesmo assim não é uma estratégia generalizante o suficiente para dar conta de neutralizar todas as palavras marcadas por gênero na língua, uma vez que a marcação de gênero se dá por várias formas, e não somente pela (como vimos, falsa) oposição entre -o e -a. Notese ainda que foram deixadas de fora outras formas de expressão de gênero, como a que ocorre em pronomes - como oposição 'minha-meu', 'ela-ela'; nos casos em que a oposição é fônica - como 'avó-avô' e 'órfã-órfão', cuja análise demandaria outras estratégias. De qualquer forma, por ser a marcação de gênero uma característica da organização interna da língua, qualquer proposta de alteração implementada artificialmente causaria um efeito em cadeia em todo o sistema, interferindo na fonotática, na morfologia, na sintaxe (no que toca à concordância), na semântica (como o falante percebe o significado dessa nova forma?), no processamento da linguagem (quais os custos cognitivos para interpretação e produção dessas formas?) e na escrita. 
A análise trazida neste artigo foi baseada na teoria disponível e consagrada sobre o sistema de gênero gramatical no $\mathrm{PB}$, cujas análises mais proeminentes são de perspectiva estruturalista. No entanto, uso esse espaço de considerações finais para apontar que a investigação sobre a marcação de gênero gramatical no PB dentro da perspectiva formal ainda está muito aquém do que vem sendo desenvolvido em outras línguas do mundo. Fugiu ao escopo deste trabalho uma discussão ampla sobre os sistemas de gênero em outras línguas e outras abordagens como, por exemplo, a relação entre a expressão linguística do gênero e o conceito de gênero, ou a percepção do gênero pelo falante do $\mathrm{PB}$, o que pretende-se levar adiante em trabalhos futuros. Por hora, reservo algumas palavras sobre outras abordagens realizadas sobre o tema.

No geral, a análise do gênero gramatical no PB se limita à estruturalista aqui apresentada. No entanto, as investigações sobre o tema se mostram mais amplas na literatura linguística internacional. Questões como de que forma o gênero é interpretado, como o gênero é atribuído, qual a realidade psicológica da expressão de gênero, qual a tipologia de gênero nas línguas, qual a correlação entre cultura e expressão gramatical de gênero são algumas questões a que se dedicam as pesquisas linguísticas pelo mundo. Uma reunião de trabalhos de abordagem formal endereçados a esses temas, a partir de sete metodologias diferentes e complementares, pode ser encontrada em Corbett $(1991,2014)$.

A maneira como o gênero é expresso nas línguas do mundo varia muito e, como já mencionado, não se restringe à oposição feminino-masculino. Em Corbett (2011) o autor discorre sobre a expressão de gênero sob o viés morfológico, sintático, semântico e psicológico, usando como base empírica a análise de casos de diversas línguas do mundo, como as línguas Zande, Dyrbal, Ket, Ojibwa, Qafar, Hausa, Godie. Corbett (2014) apresenta métodos de análise para identificar se a língua apresenta ou não sistema de gênero e para descrever o sistema com base em critérios formais e semânticos, não pela marcação morfológica, mas pelo sistema de concordância que desencadeia e pelo papel da semântica nessa atribuição. Assim, descreve uma tipologia de atribuição de gênero nas línguas que, segundo ele varia de línguas com sistemas estritamente semânticos - sem marcas morfológicas -, até sistemas estritamente formais, em que a semântica só entra em cena quando há alguma ambiguidade na forma.

McConnell-Ginett (2014) argumenta contra o que chama de mito do gênero "natural", e aponta dois fatores a serem considerados na investigação sobre expressão de gênero, que são a atribuição de gênero de base semântico-pragmática - que vai dizer o quanto o conhecimento de mundo influencia na expressão linguística do gênero - e a informação formal, ou seja, codificada na forma linguística. O grau de participação desses fatores varia conforme a língua. De acordo com a autora, há línguas de gênero conceitual (notional gender) em que há poucas marcas formais de gênero (como o Inglês) e línguas de gênero gramatical, em que a marcação de gênero é mais transparente na morfologia (como é o caso do Português). Por essa razão é importante investigar o gênero linguístico em dois níveis: como o gênero é gramaticalmente expresso, e como ele é atribuído. Ligado a isso, estratégias de 
neutralização de gênero que servem para uma língua, dificilmente servem para outras, daí o problema de se "importar" as estratégias.

No que diz respeito ao critério psicológico da expressão linguística de gênero, Schiller (2014) usa uma abordagem psicolinguística para a investigação do gênero gramatical, contribuindo para a observação de que a marcação de gênero tem efeito no processamento da linguagem, facilitando ou dificultando o processamento. Já Tsegaye e colegas (2014) descrevem experimentos realizados com o intuito de investigar o sistema de gênero na língua Konso, por meio da observação da correlação entre as expressões de gênero e número naquela língua, ambas marcas características de substantivos e pronome, como no PB. E Mithum (2014) aborda a expressão gramatical de gênero na sua relação com a cultura. A autora argumenta que, desde que se assuma que a identidade de gênero seja uma construção social e sua percepção varia conforma a cultura, é necessária uma abordagem que considere a relação entre o conceito - construído sócio-historicamente - e a expressão disponível naquela língua para exprimir o conceito.

E qual o lugar do PB neste cenário de investigação? Qual éa tipologia do sistema de marcação de gênero do PB? Qual a correspondência psicológica da interpretação do gênero gramatical no PB? Há um efeito no processamento da linguagem? Como o uso de estratégias de neutralização de gênero gramatical está (se está) influenciando a aquisição de língua falada, escrita, e processamento de linguagem? E em que nível? Todas essas questões são debatidas tendo as mais variadas línguas como objeto, admitindo-se haver um conhecimento ainda restrito e carente de debate. Se é assim no cenário internacional, o é ainda mais para o $\mathrm{PB}$, sobre o qual não se encontram ainda trabalhos que busquem responder a essas questões de interesse, nem se encontra grande variedade de abordagens sobre o tema. Há essa carência no PB e, portanto, um campo fértil a ser explorado. Espera-se que este artigo tenha contribuído para expor esta carência e provocado o interesse em se colocar o PB no mapa nas investigações atuais sobre a expressão linguística do gênero.

\section{Referências bibliográficas}

CALLOU, Dinah.; LEITE, Yonne (2004). Iniciação à fonética e à fonologia. Rio de Janeiro: Zahar.

CÂMARA Jr., Joaquim Mattoso. (6006[1970]) Estrutura da Língua Portuguesa. Petrópolis: Vozes.

.(1973) Princípios de Linguística Geral. Rio de Janeiro: Livraria Acadêmica. 
CHESTNUT, Eleanor. (2010). When I talk about a student, is it understood that he could be a girl? An analysis of on-line processing of generic pronouns. Senior Thesis. Claremont: Pomona College.

COLE, Maureen.; HILL, Frances. A.; DAYLEY, Lelan. (1983) Do masculine pronouns used generically lead to thoughts of men? In: Sex Roles, v. 9, n. 6, p. 737-750, 1983.

CORBETT, Greville. (1991). Gender. Cambridge Textbooks in Linguistics. Cambridge University Press. Cambridge.

(2014) Gender Typology. In: CORBETT, G.(ed.) The expression of gender. Berlin/Boston. De Gruyter-Mouton. p. 87-130.

(2014) The expression of gender. In: KLEIN, W. e LEVINSON, S. (eds). The expression of cognitive categories, vol 6. Berlin/Boston. De Gruyter-Mouton.

COSTA, Daniel Soares da. (2016). Morfo(lógica): flexão nominal. In: ABREU, A.; SPERANÇA-CRISCUOLO, A.C. (orgs.) Ensino de Português e Linguística. São Paulo: Contexto. p. 33-69.

GONÇALVES, Renato.; BASSO, Renato.(2010). História da Língua. Florianópolis: LLV/CCE/UFSC.

ILARI, Rodolfo.; BASSO, Renato. (2006). O português da gente: a língua que estudamos, a língua que falamos. São Paulo: Contexto.

McCONNELL-GINET, Sally. (2014). Gender and its relation to sex: the mith of "natural"gender. In: CORBETT, G.(ed.) The expression of gender. Berlin/Boston. De Gruyter-Mouton. p.3-38.

MITHUN, Marianne.(2014). Gender and culture. In: CORBETT, G.(ed.) The expression of gender. De Berlin/Boston. Gruyter-Mouton. p. 131-160.

MORAIS, João.; KOLINSKY, Régine. (2015). Psicolinguística e Leitura. In: MAIA, M. (org.) Psicolinguística, Psicolinguísticas. São Paulo: Contexto. p. 129-142.

NARO, Antony.; SCHERRE, Marta. Origens do português brasileiro. São Paulo: Parábola Editoral, 2007. 
RIO GRANDE DO SUL. Leslie Companer de Toledo. Secretaria de Comunicação A Inclusão Digital (Org.). Manual para uso não sexista da linguagem: O que bem se diz, bem se entende. Porto Alegre: Governo do Estado do Rio Grande do Sul, 2014. 112 p. Disponível em: https://edisciplinas.usp.br/pluginfile.php/3034366/mod_resource/ content/1/Manual\%2opara\%2ouso\%2on\%C3\%A30\%2osexista\%2oda\%2olinguagem. pdf . Acesso em: 17 set. 2018.

RIZZI, Cláudio. (2018). Rizzih Vlog. Disponível em https://www.youtube.com/ channel/UCbtUkddYaSFy3mxWbpXFiEg acessado em 17 de setembro de 2018.

ROCHA, Luiz Carlos de Assis. (2008). Estruturas morfológicas do Português. São Paulo: Martins Fontes.

ROLOFF, Aion; RAMOS, Ana Carolina; LOPES, Fernanda Cristina; GOULART, Lisandra Maia; OLIVEIRA, Pamela Cristine de. (2015). O Uso do 'x' como marca de gênero no Facebook: uma análise sociolinguística. In: Revista Versalete. Curitiba, Vol.3, no 4, jan.- jun. 2015. Disponível em: http://www.revistaversalete.ufpr.br/edicoes/vol3o4/26AionRoloff.pdf Acessado em 28 mar 2018.

SCHERRE, Marta.; DIAS, E.; ANDRADE, C.; MARTINS, G.. Variação dos pronomes "tu" e "você". In: MARTINS, Marco A.; ABRAÇADO, Jussara (orgs.). Mapeamento sociolinguístico do Português Brasileiro. São Paulo: Contexto, 2015. p. 109-172.

SCHILLER, Niels. (2014) Psicholinguistics approaches to the investigation of gramatical gender. In: CORBETT, G.(ed.) The expression of gender. Berlin/Boston. De Gruyter-Mouton. p.161-19o.

SCLIAR-CABRAL, Leonor. (2015). Psicolinguística e Alfabetização. In: MAIA, M. (org.) Psicolinguística, Psicolinguísticas. São Paulo: Contexto. p.113-128.

SILVA, Thaïs Cristófaro. (2015). Fonética e Fonologia do Português. São Paulo: Contexto.

TEYSSIER, P. (1997). História da língua portuguesa. São Paulo: Martins Fontes.

TIBURI, Márcia. (2018) Feminismo em comum: para todas, todes e todos. Ed. Rosa dos Tempos.

TSEGAYE, Mulugeta; MOUS, Marteen; SCHILLER, Niels. (2014). Plural as a value of Cushitic gender: Evidence from gender congruency effect experiments in Konso (Cushitic). In: CORBETT, G.(ed.) The expression of gender. Berlin/Boston. De GruyterMouton. p. 191-214. 